\title{
Wear behaviour of Zr-based in situ bulk metallic glass matrix composites
}

\author{
X F WU*, G A ZHANG and F F WU \\ School of Materials Science and Engineering, Liaoning University of Technology, Jinzhou 121001, \\ People's Republic of China
}

MS received 9 November 2014; accepted 29 November 2015

\begin{abstract}
Zr-based bulk metallic glass (BMG) and its in situ BMG matrix composites with diameter of 3 mm were fabricated by conventional $\mathrm{Cu}$-mould casting method and the dry sliding wear behaviour of the BMG and composites was investigated. Compared to the pure BMG, the composites exhibited a markedly improved wear resistance from 10 to $48 \%$ due to the existence of various volume fractions of the ductile $\beta-\mathrm{Zr}$ dendritic phase embedded in the glassy matrix. The composites showed lower friction coefficient and wear rate than the pure BMG. Meanwhile, the surface wearing of the composite with a proper amount of $\beta-\mathrm{Zr}$ dendrites was less severe compared to that of the pure BMG. The worn surface of the composite was covered with mild grooves and some fine wear debris, which exhibited the characteristic of a mild abrasive wear. The improvement of the wear resistance of the composite with the proper amount of $\beta-\mathrm{Zr}$ crystalline phase is attributed to the fact that the $\beta-\mathrm{Zr}$ crystalline phase distributed in the amorphous matrix has some effective load bearing, plastic deformation and work hardening ability to decrease strain accumulation and the release of strain energy in the glassy matrix, restrict the expanding of shear bands and cracks, and occur plastic deformation homogeneously.
\end{abstract}

Keywords. Zr-based bulk metallic glasses; in situ composites; ductile phase; wear behaviours.

\section{Introduction}

Bulk metallic glasses (BMGs) with special short-range order and long-range disorder microstructure usually exhibit unique physical, chemical and mechanical properties. In terms of mechanical properties, BMGs possess higher strength and hardness, larger elastic strain limit and better fracture toughness than their crystalline alloys. They are therefore considered to be potential structural materials in future engineering applications. Due to the combination of high hardness and toughness, BMGs are expected to exhibit superior friction and wear resistance. Contrary to the expectations, however, many investigations on the frictional and wear behaviour of BMGs indicated that the wear performance of BMGs was significantly inferior to the annealed state [1] and traditional crystalline alloys [2], which led to an abnormal phenomenon that the wear rates of BMGs with a high hardness were higher than those of traditional crystalline alloys with a low hardness such as 304 stainless steel [3]. Thus, the wear behaviour of BMGs does not follow the empirical Archard's wear equation which indicates a positive increase of wear resistance with the hardness [4,5].

Several studies reported that a proper amount of nanocrystals embedded in the amorphous matrix could increase the wear resistances of $\mathrm{Al}$ [6], $\mathrm{Cu}$ [7], $\mathrm{Zr}$ [8]-based BMGs and sprayed Fe-based metallic glass coatings [9]. However, if the volume fraction of the crystalline phases exceed certain values, the wear performance of the annealed metallic glasses which are in situ composites containing the crystals

\footnotetext{
*Author for correspondence (hgd901@126.com)
}

precipitated during annealing are significantly inferior to the metallic glasses. The investigation by Siegrist et al [10] on the wear rates of graphite-/ZrC-reinforced bulk metallic glass composites indicates that adding a low volume content of graphite and especially of $\mathrm{ZrC}$ generated a significant decrease in a coefficient of friction and the composites displayed an even lower wear rate than 100Cr6 bearing steel. Recently, Kwon et al [11] studied the wear behaviour of artificial BMG composites having various fractions of the BMG alloy and crystalline Ni phase. The composite containing less than 10 vol\% crystalline Ni showed higher wear resistance than the monolithic $\mathrm{BMG}$, while the composite containing more than $20 \mathrm{vol} \%$ crystalline $\mathrm{Ni}$ gave rise to an increase in the wear rate. Although the mechanical properties of BMG matrix composites reinforced with in situ ductile dendrites such as $b c c$ typed $\beta-\mathrm{Zr}$ etc. have been extensively studied $[12,13]$, there are no reports on the friction and wear performance of the composites so far.

This work aims to investigate the wear behaviour of $\mathrm{Zr}-$ $\mathrm{Ti}-\mathrm{Nb}-\mathrm{Cu}-\mathrm{Ni}-\mathrm{Be} \mathrm{BMG}$ composites containing various fractions of in situ formed ductile bcc typed $\beta-\mathrm{Zr}$ dendritic phase under dry sliding conditions, and the wear mechanism was analysed and discussed.

\section{Experimental}

The $\mathrm{Zr}-\mathrm{Ti}-\mathrm{Nb}-\mathrm{Cu}-\mathrm{Ni}-\mathrm{Be}$ BMG composites studied were based on $\mathrm{Zr}_{41.2} \mathrm{Ti}_{13.8} \mathrm{Cu}_{12.5} \mathrm{Ni}_{10.0} \mathrm{Be}_{22.5} \mathrm{BMG}$, commercially known as Vitreloy 1 (labelled as ZN0). $\left(\mathrm{Zr}_{75}\left(\mathrm{Ti}_{18.34} \mathrm{Nb}_{6.66}\right)_{25}\right)_{x}$ $\left(\mathrm{Cu}_{27.5} \mathrm{Ni}_{22.5} \mathrm{Be}_{50}\right)_{100-x}$ BMG composite with $x=65,75$ 
and 85 (labelled as $\mathrm{ZN1}: \mathrm{Zr}_{48.8} \mathrm{Ti}_{11.9} \mathrm{Nb}_{4.3} \mathrm{Cu}_{9.6} \mathrm{Ni}_{7.9} \mathrm{Be}_{17.5}$, $\mathrm{ZN2}: \mathrm{Zr}_{56.2} \mathrm{Ti}_{13.8} \mathrm{Nb}_{5.0} \mathrm{Cu}_{6 . .} \mathrm{Ni}_{5.6} \mathrm{Be}_{12.5}$ and $\mathrm{ZN} 3: \mathrm{Zr}_{63.7} \mathrm{Ti}_{15.6}$ $\mathrm{Nb}_{5.7} \mathrm{Cu}_{4.1} \mathrm{Ni}_{3.4} \mathrm{Be}_{7.5}$ ) were designed. The composites contained ductile $b c c \beta-\mathrm{Zr}$ phase comprised of $\mathrm{Zr}, \mathrm{Ti}, \mathrm{Nb}$ and $\mathrm{Cu}$ in $\mathrm{Zr}_{47} \mathrm{Ti}_{12.9} \mathrm{Nb}_{2: 8} \mathrm{Cu}_{11} \mathrm{Ni}_{9: 6} \mathrm{Be}_{16: 7}$ metallic glass matrix $[14,15]$. The crystalline phase precipitates directly from the melt, leading to a dendritic structure. The materials contained a relatively fine dispersion of dendrites with the second phase regions separated by the metallic glass matrix [15].

Ingots of the $\mathrm{ZNO}, \mathrm{ZN} 1, \mathrm{ZN} 2$ and $\mathrm{ZN} 3$ were prepared by arc melting the mixture of pure metals $(\mathrm{Zr}, \mathrm{Ti}, \mathrm{Nb}, \mathrm{Cu}, \mathrm{Ni}$ and $\mathrm{Be}$ ) with a purity of more than $99.9 \%$ under a Ti-gettered Ar atmosphere. For getting a homogeneous master alloy, the raw elements of $\mathrm{Zr}$ and $\mathrm{Nb}$, which possess the highest melting temperatures in the system, were first arc melted to produce an intermediate binary $\mathrm{Zr}-\mathrm{Nb}$ alloy. The master alloys were then made by arc melting the mixture of the intermediate alloy and the other pure metals. The ingots were remelted four times to ensure homogeneity of the samples. Fifty millimetre length cylindrical rods with a diameter of $3 \mathrm{~mm}$ were prepared by pouring liquid metal, which was melted using induction furnace, through a quartz nozzle into a copper mould under certain argon pressure as well as purified argon atmosphere.

The structures of samples were detected by X-ray diffraction (XRD) pattern by using a Rigaku X-ray diffractometer $(\mathrm{CuK} \alpha$ radiation). The microstructures of the composites were investigated by a optical microscope (OM).

To evaluate the dry sliding wear behaviours of the composites, dry sliding abrasive wear tests were performed using a pin-on disc machine under an applied load of $120 \mathrm{~N}$. The specimens of the $\mathrm{ZN} 0, \mathrm{ZN} 1, \mathrm{ZN} 2$ and $\mathrm{ZN} 3$ rods with $3 \mathrm{~mm}$ in diameter were cut into disks with $10 \mathrm{~mm}$ thickness. A bearing steel ring was employed as the counterface. Before and after the test, the pin was cleaned with ethanol and weighed. Each test was done for $10 \mathrm{~min}$ with $1200 \mathrm{rpm}$ rotation speed. The mass lost for each specimen was calculated by accurately weighing the specimens before and after wear tests with an electronic balance of $\pm 0.00001 \mathrm{~g}$ precision. The wear rate was calculated from the results of the weight loss and sliding distance. The worn surface morphologies of the composites were investigated by a scanning electron microscope (SEM).

\section{Results}

Figure 1 shows the XRD patterns and optical microstructures for the as-cast $\mathrm{ZN} 0, \mathrm{ZN} 1, \mathrm{ZN} 2$ and $\mathrm{ZN} 3$. As expected, the XRD pattern from the ZN0 consists only a broad peak with no evidence of any crystalline Bragg peaks, indicating that the as-cast sample is fully amorphous. On the other hand, a few sharp diffraction peaks corresponding to crystalline phases superimposed on the broad amorphous peaks were observed for the other three alloys, which implies that the ZN1, ZN2 and ZN3 are partially amorphous with a significant fraction of crystalline phases. The crystalline phase existing in the three alloys was identified as $b c c \beta-\mathrm{Zr}$ solid solution superimposed on a broad scattering feature characteristic of an amorphous phase. No other phases were detected from the diffraction patterns of the three composite samples. The peaks of the crystalline phase increase in an order from the $\mathrm{ZN} 1, \mathrm{ZN} 2$ to $\mathrm{ZN} 3$, indicating that the amount of the $b c c \beta-\mathrm{Zr}$ phase in the $\mathrm{ZN} 1, \mathrm{ZN} 2$ and $\mathrm{ZN} 3$ increases in an order. This result demonstrates that the present composites consist of $b c c \beta-\mathrm{Zr}$ solid solution and glass matrix. The optical microstructures presented in the inset of the XRD patterns further reveal that the $b c c \beta-\mathrm{Zr}$ phases in the $\mathrm{ZN} 1, \mathrm{ZN} 2$ and ZN3 alloys display dendritic morphologies and are uniformly distributed within featureless glass matrixes. The volume fractions of the dendrites in $\mathrm{ZN} 1, \mathrm{ZN} 2$ and $\mathrm{ZN} 3$ are 12.7, 25.1 and 34.6 vol\%, respectively, and their dendritic sizes change from small to large.

The Vicker's hardness values for the as-cast ZN0, ZN1, $\mathrm{ZN} 2$ and ZN3 before and after wear are shown in figure 2 .

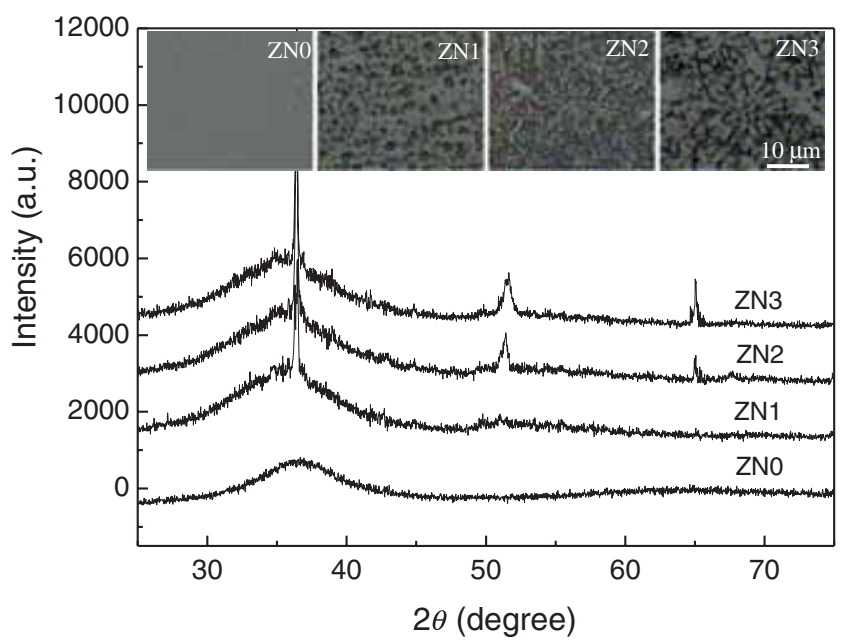

Figure 1. XRD patterns of the as-cast $\mathrm{ZNO}, \mathrm{ZN} 1, \mathrm{ZN} 2$ and $\mathrm{ZN} 3$ rod samples. The inset shows the optical micrographs of the samples.

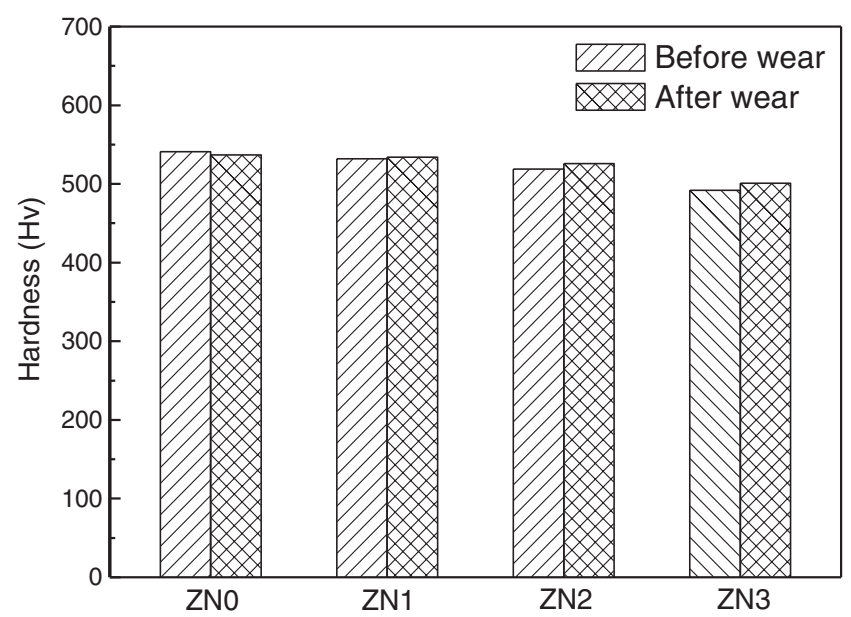

Figure 2. Hardness for the as-cast $\mathrm{ZN} 0, \mathrm{ZN} 1, \mathrm{ZN} 2$ and $\mathrm{ZN} 3$. 
It is seen that the hardness values of $\mathrm{ZN} 1, \mathrm{ZN} 2$ and $\mathrm{ZN} 3$ are lower than that of ZN0 before wear. After wear, the hardness value of the ZN0 decreases slightly, while the hardness values of the ZN1, ZN2 and ZN3 increase slightly. These two phenomena may be ascribed to the thermal softening caused by inhomogeneous shear deformation of metallic glasses for the $\mathrm{ZNO}$ and the work hardening caused by the various fractions of the $\beta-\mathrm{Zr}$ crystalline phase embedded in the glassy matrix for the $\mathrm{ZN} 1, \mathrm{ZN} 2$ and $\mathrm{ZN} 3$.

Figure 3 shows the average friction coefficients (COF) of the ZN0, ZN1, ZN2 and ZN3. The values of COF of samples ZN0 ZN1, ZN2 and ZN3 are between 0.34 and 0.43 . The ZN2 shows the lowest COF of about 0.34 . The ZN0 and ZN1 display relatively similar intermediate values of about 0.39 and 0.37 , respectively, which are roughly equivalent to the values of $\mathrm{Cu}$ - and $\mathrm{Zr}$-based $\mathrm{BMG}$ alloys reported in refs $[16,17]$. The highest COF of about 0.43 was generated from the $\mathrm{ZN} 3$.

Figures 4 and 5 show the variation of the wear rate in various samples and the appearance of the worn materials,

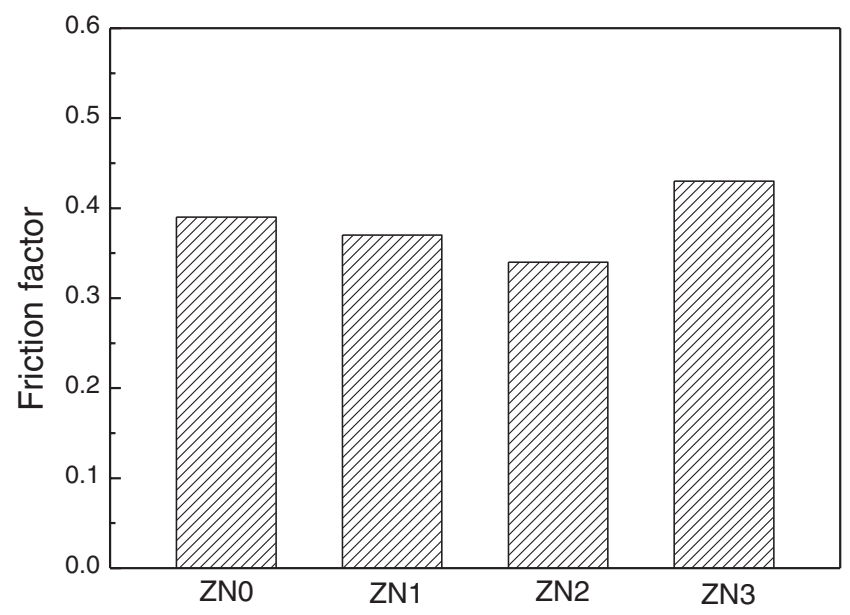

Figure 3. Friction coefficients for the as-cast ZN0, ZN1, ZN2 and ZN3.

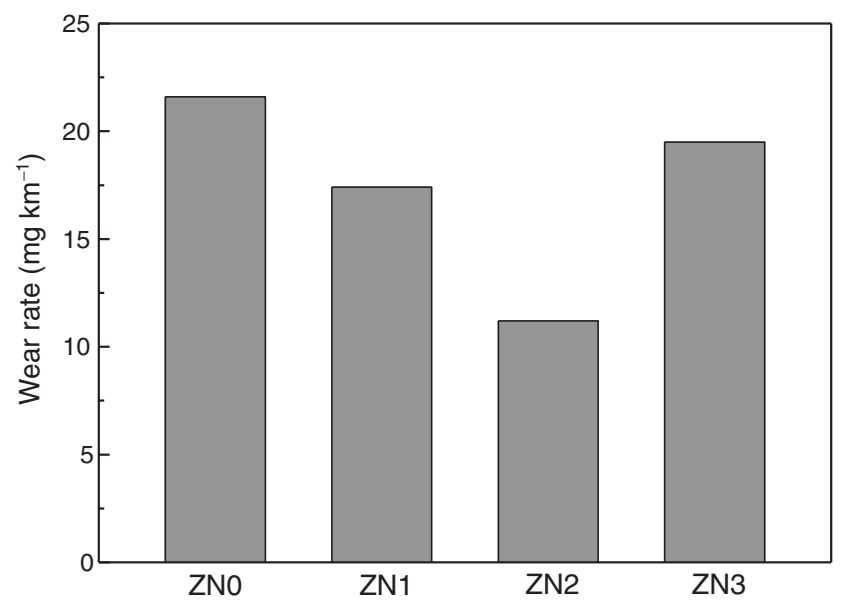

Figure 4. Wear rates for the as-cast ZN0, ZN1, ZN2 and ZN3. respectively. It is clear from figure 4 that all the composite (ZN1, ZN2 and ZN3) samples exhibited a lower wear rate than the monolithic BMG (ZN0) sample, which is related to the $\beta-\mathrm{Zr}$ phase in the $\mathrm{ZN} 1, \mathrm{ZN} 2$ and $\mathrm{ZN} 3$. Interestingly, it is not true that the more the $\beta-\mathrm{Zr}$ phase, the lower the wear rate, but the sample $\mathrm{ZN} 2$ containing second most second $\beta$ $\mathrm{Zr}$ phase displayed a minimum wear rate and the wear rate decreases in an order from the ZN0, ZN3, ZN1 to ZN2. The trend of variations in the heights of the tested samples was corresponded to that of variations in the wear rates, i.e., the lower the wear rate, the higher the sample height (figure 5). In addition, it is observed from figure 5 that there are different sized turn-up on the worn surfaces of ZN1, ZN2 and $\mathrm{ZN} 3$, indicating that varying degrees of plastic flow occurred on their worn surfaces, when sample contacted with rotating counterface during dry sliding wear.

A comparison of the hardness and wear rate of monolithic BMG (ZN0) with those of the composites ZN1, ZN2 and $\mathrm{ZN} 3$ indicates that the formation of soft $\beta-\mathrm{Zr}$ phase in $\mathrm{BMG}$ improved the wear resistance of BMG from 10 to $48 \%$, which appears to be not followed by Archard's equations, according to which sliding wear resistance is roughly proportional to the material's hardness. However, in various wear mechanisms applied, hardness is not the only index of the wear resistance of materials. Indeed, Kwon et al [11] reported that Fe-based BMG composites containing less than $10 \mathrm{vol} \%$ soft crystalline Ni displayed higher wear resistance than the monolithic BMG. Kim et al [18] revealed that the AISI 1045 steel specimen with higher ductility, that were tempered, showed a lower wear rate than the specimen with lower ductility that were not tempered, though their hardness values are similar and there is no simple relationship between the hardness and the wear resistance.

To investigate changes in the wear mechanism of the materials, their worn surfaces were observed by SEM. Figures 6 and 7 show SEM micrographs of the centre and edge of the worn surfaces of (a) ZN0, (b) ZN1, (c) ZN2 and (d) ZN3

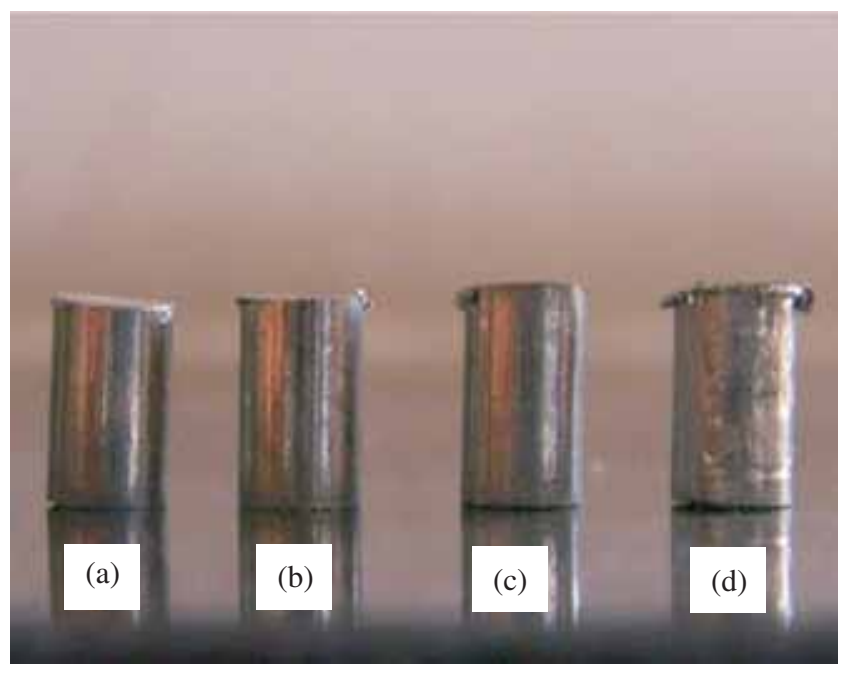

Figure 5. The appearance of worn materials: (a) ZN0, (b) ZN1, (c) ZN2 and (d) ZN3. 
samples tested under an applied load of $120 \mathrm{~N}$, respectively. The centric worn surfaces of ZN0 and ZN1 showed a very rough surface with the presence of distinct grooves induced by ploughing and particles, especially the groove of the worn surface of the ZN0 was wider and deeper than that of the ZN1. Plastic deformation was evident on both sides of the grooves, and a closer examination at high magnification (figure 6a) showed that some crushed flakes with some cracks, which were generated from the pile-up region on the edges of the grooves, were observed at the worn surface of the $\mathrm{ZN} 0$ reflecting that the brittle fracture dominated the damage on the worn surface, indicating that abrasion was the main wear mechanisms of ZNO. Compared to the worn surfaces of the $\mathrm{ZN} 0$ and $\mathrm{ZN} 1$, that of the ZN2 showed relatively smooth planes and there were mild grooves with some fine wear debris parallel to the sliding direction on the worn surface. This kind of morphology exhibited the characteristic of mild abrasive wear. Therefore, it is obvious that the damage occurred in the worn surface of the ZN2 was much less severe than that of the ZN0. However, the appearance of the ZN3 worn surface was significantly different to those of the ZNO, ZN1 and $\mathrm{ZN} 2$, the worn surface had a large number of rough detached damages and was covered by severe flakes and long grooves, which is typical feature associated with both adhesive and abrasive wears. This surface morphology formed as hard asperities on the steel counterface, or hard particles in between the pin and the disk ploughed or cut into the pin and eventually removed small fragment or ribbon-like strips of material from the worn surface primarily through ductile processes. In addition, it is observed from figure 7 that some large cracks appeared on the edges of the worn surfaces of the ZN0 and ZN1 (figure 7a and b). The ZN2 has a smooth surface edge (figure 7c), while ZN3 has a large pit formed by plastic deformation (figure 7d).

The wear debris was examined by SEM to further determine the wear mechanism of the material. After the wear tests, the wear debris was collected at a sliding distance of $2.5 \mathrm{~km}$. Figure 8 shows wear debris collected from (a) ZN0, (b) ZN1, (c) ZN2 and (d) ZN3. The wear debris of ZN0 and ZN1 comprised mostly flake-like particles with sharp edges and corners. Some large debris displayed much larger sizes of more than $200 \mu \mathrm{m}$ and some microcracks were observed on the surface of $\mathrm{ZNO}$, which further confirms the brittle fracture of the ZN0. The wear debris of the ZN2 is different from those of ZN0 and ZN1 and consists of fine particles. In contrast to the $\mathrm{ZN} 2$, the debris of $\mathrm{ZN} 3$ comprises large fragments on which superimposed debris were observed. It appears that a mass of plastic deformation occurred in the fragments and flake-like particles often developed during the adhesive wear. The formation of the wear debris suggests that adhesive wear governs the wear of the $\mathrm{ZN} 3$.

\section{Discussion}

In recent studies of the wear behaviour of BMGs, delamination and microcracks are considered as the main wear mechanisms [19]. During wear tests, delamination is caused on the
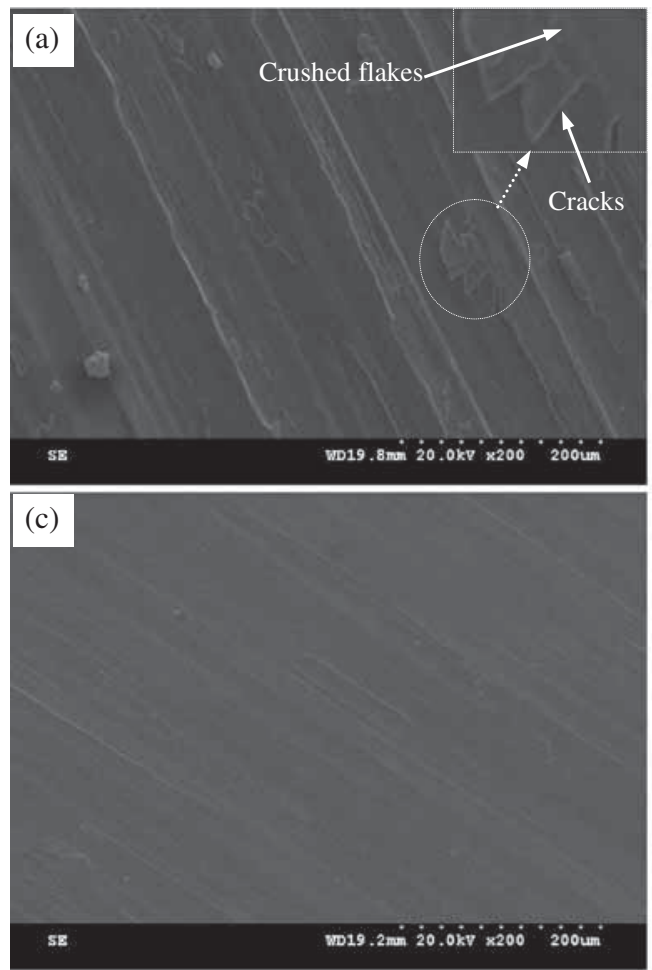
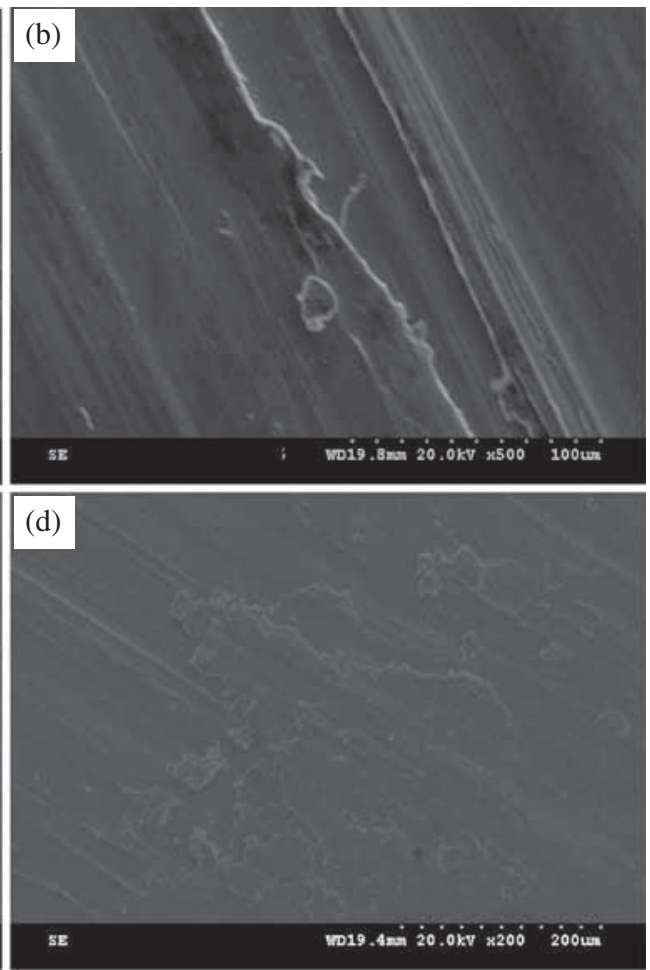

Figure 6. SEM micrographs of worn surfaces of the materials: (a) ZN0, (b) ZN1, (c) ZN2 and (d) ZN3. 


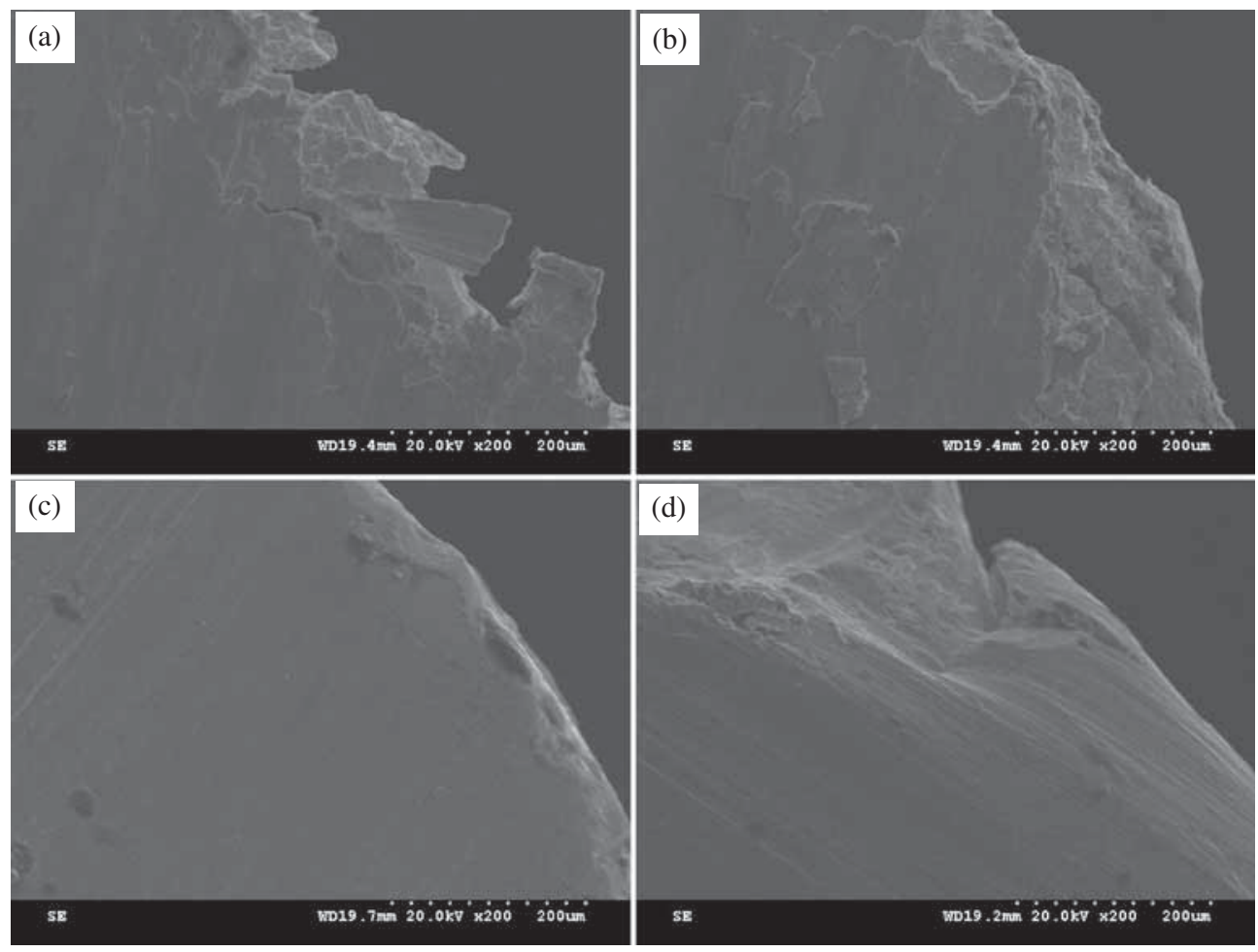

Figure 7. SEM micrographs of the edges of the worn surfaces of the materials: (a) ZN0; (b) ZN1; (c) $\mathrm{ZN} 2$ and (d) ZN3.
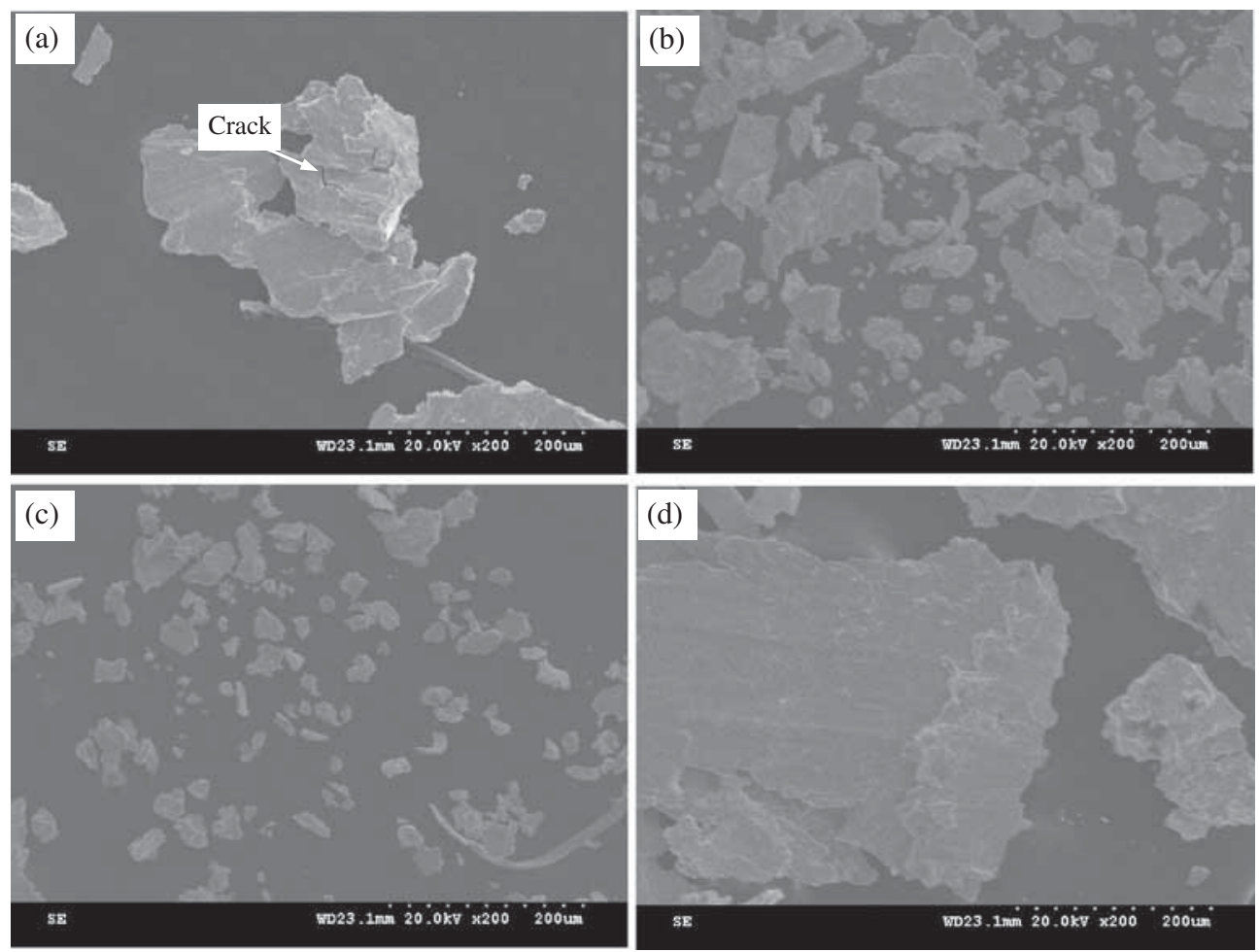

Figure 8. SEM micrographs of worn surfaces of the composites: (a) ZN0, (b) ZN1, (c) ZN2 and (d) ZN3. 
worn surface of BMGs by the nucleation and propagation of subsurface microcracks, and when microcracks are long enough material breaks away forming craters and grooves on the sliding surface [7]. The microcracking was revealed by scratch indentation and acoustic emission measurements [20]. In this study, the delamination and subsequent cracks were observed on the worn surface of the pure metallic glass sample ZN0, but they appeared in pile-up region on the edges of the grooves, but not in the groove region. Metallic glass is intrinsically brittle, which is easy to be confirmed by the cracking of the worn surface of the sample edge of ZN0 (figure 7a). However, plastic deformation also occurs during wear of metallic glasses in the form of localized shear bands due to the formation of more free volume [21], which may result in softening of metallic glasses. The decrease of elastic modulus [22] and Vicker's hardness of the ZNO (figure 2) at positions close to the wear track after the wear test indicates this behaviour. The softening of the worn surface of metallic glasses leads to the formation of grooves and material pileup on the edges of the grooves, which were found in refs $[23,24]$. The pile-up material was flattened and delaminated by the load when it is in contact with the bearing steel disc. The delaminated material experienced tensile stress at the trailing of the rotating disc. Due to the lack of plasticity in the metallic glasses, crack initiation is easy on the delaminated material (figure 6a). Upon disc rotation, the stress in the delamination material may be released by the crack propagation and then extended, until finally, peeling off was induced from the edges of the grooves. Furthermore, some peeling delamination layers adhered to the counter surface, forming pile-up on the counter surface compacting and cutting the worn surface of metallic glasses, which led to the formation of wider and deeper grooves (figure 6a) and high wear rate (figure 4). The peeling delamination layers which were not adhered formed flake-like BMG debris (figure 8a).

It is apparent from the wear test results and the SEM observations that the Zr-based BMG composites with lower hardness exhibited better wear resistance than the pure BMG ZNO with higher hardness, contrary to what might be expected. The unusual phenomenon for the BMG and its composites was observed in some other alloys and composites [11,18]. The high wear resistance of the Zr-based BMG composites should be ascribed to the presence of in situ formed $b c c$ typed $\beta-\mathrm{Zr}$ dendritic phase embedded in the glassy matrix. The $\beta-\mathrm{Zr}$ crystalline phase in the composites is ductile and not brittle due to its simple body cubic structure, and does not crack and is debonded from the surface by the shear force during dry sliding, and then 'three-body wear' may not occur, which contrasts with brittle crystalline phase precipitated from $\mathrm{Zr} \mathrm{BMG}$ by annealing when the volume fraction of these crystals is up to $40 \%$ volume, although the size of the crystals is very small [25]. On the other hand, for the ZN1, as only a few dendrites were embedded in its glassy matrix, the pile-up and crushed flakes were observed at the worn surface as the ZN0 (figure $6 a$ and b), reflecting that the glassy matrix dominated their worn process. The crushed flakes, however, did not break. In addition, no crack appeared in the wear debris of $\mathrm{ZN} 1$. These are attributed to the ductile $\beta-\mathrm{Zr}$ phase that was assured to contribute to the decrease of strain accumulation and the release of strain energy in the glassy matrix adjacent to $\beta-\mathrm{Zr}$ dendritic phase by dislocation motion, twinning and phase transformation so it could be prevented or retarded the cracks from being formed and extended within the matrix, resulting in the formation of the crushed flakes without cracks in pile-up region on the worn surface and the wear debris without cracks on the wear track. So the crushed flakes is not easy to fall off and the wear resistance of the material is improved to some extent (figures 4 and 5). ZN2 has the smallest rate in the tested material and in addition to the above two points, the another reason for the ZN2's best wear resistance is the presence of the proper amount of ductile dendrites, which can seed the initiation of organized shear band patterns during wear, confine the propagation of a small amount of shear bands and trigger the formation of more multiple shear bands. Therefore, plasticity is distributed more homogeneously in the shear band patterns and the softening of the worn surface of metallic glasses is retarded, which leads to the disappearance of material pile-up on the edges of the grooves and subsequent delamination, cracking and falling off, eventually forming narrow and shallow grooves (figure 6c) and displays a smallest wear rate (figures 4 and 5). Again, the rolling compaction of a bearing steel ring which was employed as the counterface on worn surface of the composites resulted in the increase in the hardness of the composites (figure 2), which reveals the occurrence of work hardening and is beneficial to the decrease of the wear rates of the composites. The work hardening may be ascribed to the increase of the dislocation densities of the $\beta-\mathrm{Zr}$ crystalline phase embedded in the glassy matrix. The increase of the dislocation densities of crystalline phase was confirmed by Zandrahimi et al's [26] investigation on dislocation characterization in worn Al-Si alloys. For the ZN2, enough work hardening was caused by the proper amount of $\beta-\mathrm{Zr}$ dendrites embedded in the glassy matrix (figure 2). Therefore, it can be concluded that the improvement of the wear resistance of $\mathrm{ZN} 2$ with the proper amount of $\beta-\mathrm{Zr}$ crystalline phase distributed in the amorphous matrix is attributed to the fact that the proper amount of $\beta-\mathrm{Zr}$ crystalline phase has some effective load bearing, plastic deformation and work hardening ability, which leads to a positive effect on the improvement of the wear resistance by decreasing strain accumulation, releasing strain energy in the glassy matrix, restricting the expanding of shear bands and cracks, and occurrence of plastic deformation homogeneously. Finally, for the ZN3, the volume of its $\beta-\mathrm{Zr}$ dendritic phase is larger than a certain value, resulting in the generation of large plastic deformation occurred on the centre and edge of the worn surface of the material (figures $5 \mathrm{~d}$ and $7 \mathrm{~d}$ ) and the increase of a wear rate (figures 4 and 5) but its wear rate is smaller than that of the pure BMG ZN0 (figures 4 and 5), which also is due to the above beneficial effects of $\beta-\mathrm{Zr}$ dendritic phase on wear resistance, though the generation of large plastic deformation caused by a large amount of dendritic in ZN3 may damage to the wear resistance in a certain degree. 


\section{Conclusion}

(1) Zr-based bulk metallic glass (BMG) ZN0 and its in situ bulk metallic glass matrix composites $\mathrm{ZN} 1, \mathrm{ZN} 2$ and $\mathrm{ZN} 3$ with diameter of $3 \mathrm{~mm}$, which contain the various fractions of the in situ formed $\beta$-Zr crystalline phase were fabricated by conventional $\mathrm{Cu}$-mould casting method.

(2) Dry sliding wear characteristics of the composites are superior to that of the pure BMG. The wear rate and friction coefficient decrease in the order of $\mathrm{ZN} 0, \mathrm{ZN} 3$, $\mathrm{ZN} 1$ and $\mathrm{ZN} 2$, and the wear rate of $\mathrm{ZN} 2$ deceases by $48.1 \%$ compared to the ZNO.

(3) The worn surface of the ZN0 was characterized by flakes, delamination, pile-up and deep grooves which showed a severe abrasive wear mode, whereas that of the $\mathrm{ZN} 2$ was less severe and there were shallow grooves with some fine wear debris on the worn surface, which exhibited the characteristic of mild abrasive.

(4) The debris of the ZN0 and ZN2 samples showed a similar lamellar morphology. The former showed large sizes with the width of more than $200 \mu \mathrm{m}$, and the latter showed much smaller sizes of less than $50 \mu \mathrm{m}$.

(5) The improvement of the wear resistance of the composite $\mathrm{ZN} 2$ with the proper amount of $\beta-\mathrm{Zr}$ crystalline phase distributed in the amorphous matrix is attributed to the fact that it has some effective load bearing, plastic deformation and work hardening ability, which lead to a positive effect on the improvement of the wear resistance by decreasing strain accumulation, releasing strain energy in the glassy matrix, restricting the expanding of shear bands and cracks, and occurrence of plastic deformation homogeneously.

\section{Acknowledgements}

Funding by education fund item of Liaoning Province under grant no. L2013250, programme for Liaoning Excellent Talents in the university under grant no. LJQ2014064 and for Liaoning BaiQianWan Talents under grant no. 2014921056 are gratefully acknowledged.

\section{References}

[1] Anis M, Rainforth W M and Davies H A 1994 Wear 172135

[2] Blau P J 2001 Wear 250431

[3] Tam Rex C Y and Shek C H 2004 J. Non-Cryst. Solids 347 268

[4] Archard J F 1953 J. Appl. Phys. 24981

[5] Kwon D H, Lee K M, Park E S, Kim H J, Bae J C and Huh M Y 2012 J. Alloys Compd. 536S S99

[6] Gloriant T 2003 J. Non-Cryst. Solids 31696

[7] Tam C Y and Shek C H 2004 Mater. Sci. Eng. A384 138

[8] Eckert J, Kühn U, Mattern N, Reger-Leonhard A and Heilmair M 2001 Scripta Mater. 441587

[9] Yoon S H, Kim J W, Kim B D and Lee C H 2010 Surf. Coat. Technol. 2051962

[10] Marco E S, Esther D A and Jörg F L 2007 Intermetallics 15 1228

[11] Kwon D H, Park E S, Huh M Y, Kim H J and Bae J C 2011 J. Alloys Compd. 509S S105

[12] Szuecs F, Kim C P and Johnson W L 2011 Acta Mater. 49 1507

[13] Qiao J W, Zhang Y and Chen G L 2009 Mater. Des. 303966

[14] Lee S Y, Kim C P, Almer J D, Lienert U, Ustundag E and Johnson W L 2007 J. Mater. Res. 22538

[15] Huang Y L, Bracchi A, Niermann T, Seibt M, Danilov D, Nestler B and Schneider S 2005 Scripta Mater. 5393

[16] Fleury E, Lee S M, Ahn H S, Kim W T and Kim D H 2004 Mater. Sci. Eng. 375-377A 276

[17] Bhatt J, Kumar S, Dong C and Murty B S 2007 Mater. Sci. Eng. 458A 209

[18] Kim S H and Kim Y S 1999 Metals Mater. 5267

[19] Greer A L, Rutherford K L and Hutchings M 2002 Int. Mater. Rev. 4787

[20] Prakash B 2005 Wear 258217

[21] Bhowmick R, Raghavan R and Chattopadhyay K 2006 Acta Mater. $\mathbf{5 4} 4221$

[22] Liu Y, Zhu Y T, Luo X K and Liu Z M 2010 J. Alloy Compd. $\mathbf{5 0 3} 138$

[23] Tariq N H, Hasan B A and Akhter J I 2009 J Alloy Compd. 469179

[24] Duan H T, Tu J S, Du S M, Kou H C, Li Y, Wang J P et al 2011 Mater. Des. 324573

[25] Bian Z, Chen G L, He G and Hui X D 2001 Mater. Sci. Eng. 316A 135

[26] Zandrahimi M and Rezvanifar A 2012 Tribol. Lett. 46255 